\title{
A 'Política' nos jornais durante período eleitoral: uma perspectiva da cobertura jornalística nas eleições municipais de 2008 em três grandes municípios do interior do Paraná
}

\section{Politics in the newspapers during the elections: an analysis of the press coverage of the 2008 municipal elections in three large cities of the inland Paraná}

\author{
Emerson Urizzi Cervi* \\ Ana Paula Hedler** \\ Camila Wada Engelbrecht ${ }^{* * *}$ \\ Cintia Amaro Damasceno****
}

\begin{abstract}
Resumo: O artigo apresenta resultados de pesquisa do grupo "Mídia, Política e Atores Sociais" da Universidade Estadual de Ponta Grossa, no que se refere à temática apresentada pelos jornais Diário do Norte, Folha de Londrina, Diário dos Campos e Jornal da Manhã durante o período eleitoral de 2008. O objetivo é mostrar quais temas mais aparecem na cobertura política dos jornais e qual a presença das campanhas eleitorais para prefeito dos municípios-sede dos periódicos. Para isso foram pesquisados os três meses que abrangem o período eleitoral que são: agosto, setembro e outubro de 2008. A questão que move o trabalho é discutir qual a participação do tema eleitoral na mídia durante as disputas eleitorais.
\end{abstract}

Palavras-chave: Política. Cobertura jornalística. Campanha eleitoral 2008 no Brasil.

\begin{abstract}
This article presents the results of the research undertaken by the "Media, Politics and Social Actors" group of the Universidade Estadual de Ponta Grossa, regarding the topics presented by the Diário do Norte, Folha de Londrina, Diário dos Campos and Jornal da Manhã newspapers during the 2008 elections. The aim is to show which issues appear more frequently in the press coverage and how often the campaigns for mayor are mentioned on the local newspapers. In order to do so, three months of the electoral period were analyzed: August, September and October of 2008. The purpose of this work is to discuss the relevance of the electoral theme in the newspapers during the elections.
\end{abstract}

\footnotetext{
* Dr. Ciência Política Instituto Universitário de Pesquisas de RJ. Professor Universidade Estadual de Ponta Grossa (UEPG). Email: eucervi@uepg.br

** Jornalista, Mestranda Ciência Política Universidade Federal do Paraná (UFPR). Email: ana_hedler@hotmail.com

*** Graduanda Jornalismo UEPG (Provic). Email: caca_engel@yahoo.com.br

**** Graduanda Jornalismo UEPG (Provic). Email: cintiamaro@hotmail.com
} 
Keywords: Politics. Press coverage. 2008 electoral campaign in Brazil.

Recebido em: 26/12/2009. Aceito em: 01/09/2010.

\section{Discussão conceitual}

Os meios de comunicação têm um papel relevante nas sociedades contemporâneas. Segundo Michael Kunczik, mesmo naquelas nações mais fracas e instáveis, são eles que servem como inspetor geral de todo o sistema político e que proporcionam a crítica pública necessária para garantir a integridade política por parte daqueles que detêm o poder. (KUNCZIK, 2002). É importante atentar para o conteúdo que está sendo transmitido pela mídia como, também, é necessário perceber que tratamento o conteúdo está recebendo, principalmente nas coberturas especiais, como é o caso das campanhas políticas. Como Luis Felipe Miguel reconhece

[...] a mídia é, nas sociedades contemporâneas, o principal instrumento de difusão das visões de mundo e dos projetos políticos; dito de outra forma é o local em que estão expostas as diversas representações do mundo social, associadas aos diversos grupos e interesses presentes na sociedade. (MIGUEL, 2002, p. 6).

Entendendo desta forma, a mídia torna-se o lugar no qual se desenvolvem e se discutem assuntos pertinentes à sociedade, torna-se um espaço público. Habermas (2003) define a esfera pública como aquela que é contrária à esfera do privado e é onde se incluem os atores políticos ou, então, a mídia que serve para que o público se comunique. Segundo Habermas é somente à luz da esfera pública que os assuntos e temas ganham liberdade e continuidade, pois é ali que os temas estão visíveis a todos e estão disponíveis para o debate. $A$

[...] influência dos media é admitida sem discussão, na medida em que ajudam a estruturar a imagem da realidade social, a longo prazo, a organizar novos elementos da mesma imagem, a formar novas opiniões e crenças. (WOLF, 2006, p. 143).
Dessa forma, os meios de comunicação auxiliam na formação da opinião pública acerca dos temas que são trazidos pelos mesmos e acabam por agendar os assuntos nos quais as pessoas vão pensar, mesmo que essa não seja a intenção principal dos jornalistas. (McCOMBS, 1997).

Segundo a teoria do agendamento midiático os meios de comunicação não pretendem persuadir a massa, mas "apresentam ao público uma lista daquilo sobre o que é necessário ter uma opinião e discutir". (WOLF, 2006, p.145). Por isso, faz-se necessário pesquisar o que eles estão divulgando, pois é capaz de indicar o que os editores e jornalistas consideram como assuntos relevantes para serem discutidos na comunidade. A partir desses princípios teóricos, o grupo de pesquisa em "Mídia, Política e Atores Sociais" da Universidade Estadual de Ponta Grossa (UEPG) pesquisou os meses de agosto, setembro e outubro de 2008, a cobertura feita pelos jornais locais Diário do Norte, Folha de Londrina, Diário dos Campos e Jornal da Manhã a respeito das disputas eleitorais para as prefeituras dos municípios-sede de cada um dos periódicos. Com isso pretende-se verificar o que os editores desses veículos consideram como assuntos relevantes para o debate público a partir do momento em que divulgam notícias, manchetes e reportagens sobre o tema: disputa eleitoral.

Os meios de comunicação, devido à sua importância na sociedade contemporânea, são objeto de diferentes interesses e também influem no modo com os integrantes das sociedades contemporâneas constroem a visão de mundo. A mídia potencializa o alcance à informação, levantando discussões na esfera pública. De acordo com Gomes (1998, p.155), Habermas define a esfera pública como

[...] o âmbito da vida social em que os interesses, vontades e pretensões que comportam consequências concernentes a uma 
coletividade apresentam-se discursivamente e argumentativamente de forma aberta e racional.

A esfera pública é, em sociedades complexas, constituída principalmente a partir da atuação dos meios de comunicação de massa na difusão dos debates a respeito dos temas públicos.

Ao inserir determinadas questões no debate da esfera pública, os meios de comunicação promovem a definição de uma agenda para os debates públicos, processo identificado pela hipótese da agenda setting, que defende que:

[...] em consequência da ação dos jornais, da informação e dos outros meios de informação, o público é ciente ou ignora, dá atenção ou descuida, enfatiza ou negligencia elementos dos cenários públicos. As pessoas tendem a incluir ou excluir dos próprios conhecimentos o que a mídia inclui ou exclui do próprio conteúdo. Além disso, o público tende a conferir ao que ele inclui uma importância que reflete de perto a ênfase atribuída pelos meios de comunicação de massa aos acontecimentos, aos problemas, ás pessoas. (SHAW: in WOLF, 2003, p. 143)

A partir da hipótese do agendamento pelos meios de comunicação, é possível entender a relevância dos veículos para a sociedade. Luis Felipe Miguel afirma que

[...] o impacto da definição da agenda pelos meios é perceptível não apenas para o cidadão comum, que tende a identificar como mais importantes as questões destacadas pelos meios de comunicação, mas também no comportamento de líderes políticos e de funcionários públicos que se veem na obrigação de dar uma resposta àquelas questões (MIGUEL, 2002, p. 11).

Nesse contexto, a mídia envolve critérios de seleção que separam os assuntos de acordo com a sua importância. Nos meios impressos, existem diferentes espaços de visibilidade que transferem mais ou menos relevância a determinado fato. Uma vez inserido no sistema de produção das notícias, os temas ganham distintas importâncias em função do espaço que ocupam nos veículos informativos. As notícias de primeira página são consideradas as principais abordadas pela edição diária dos periódicos.
A primeira página dos jornais diários tem a função, entre outras, de atrair a atenção os leitores, já que enquanto produto, os jornais estão sujeitos à concorrência de mercado. Para Deodoro José Moreira "é a primeira página que atrai ou não o leitor sua decisão de ler depende do grau de criatividade" (MOREIRA, 2004, p.31). Portanto o processo de produção de um jornal exige uma seleção, baseada no público alvo do veículo, para que a hierarquização das notícias - segundo sua importância - seja expressa na disposição dos temas nas capas dos jornais. Essa seleção é baseada nos chamados critérios de noticiabilidade, que tem a função de sistematizar e hierarquizar informações, segundo importância dada a eles.

A disposição das notícias expressa a linha editorial dos diferentes jornais, revelando os critérios pelos quais determinadas notícias são consideradas importantes e ganham visibilidade. Por este motivo, a visibilidade é um fator caro aos jornais e desperta o interesse de diferentes grupos sociais que pressionam e interferem no processo de produção jornalística. Segundo Luis Felipe Miguel

[...] a mídia, é nas sociedades contemporâneas, o principal investimento de difusão das visões de mundo e dos projetos políticos (...) é o local em que estão expostas as diversas representações do mundo social (MIGUEL, 2002, p. 6).

A busca pela visibilidade é um dos principais elementos que configuram a relação entre os campos político e midiático. Ao mesmo tempo em que os políticos necessitam dos meios de comunicação para conseguir visibilidade e se fazer presente no debate público, a mídia depende do campo político para veicular os acontecimentos que nele se passam e desperta o interesse social pela representatividade e importância social. Essa interdependência configura adaptações e transformações nos modelos tradicionais de representação social. A fragmentação da sociedade contemporânea dificultou a identificação dos eleitores com partidos políticos, resultando no declínio da política partidária. É no debate a respeito dessa crise de representação que os meios de comunicação passam a atuar e se consolidam como veiculadores do discurso político. Essa relação de dependência entre os dois 
campos influi na organização de atores internos, principalmente do campo político, que passa a sistematizar suas ações segundo a lógica dos diferentes meios de comunicação.

A dinâmica entre espaço da mídia e da política se evidencia - principalmente nas campanhas eleitorais - em função de sua importância tanto para o debate público quanto para a organização da elite política no Estado. É através da visibilidade do assunto nas primeiras páginas que se pode verificar a importância do tema para os veículos de comunicação. Durante o período de campanha, o campo político é colocado em evidência e debatido de forma a legitimar a democracia.

O discurso político precisa se adaptar ao novo ambiente gerado pelos meios de comunicação de massa, bem como a prática política que incorpora os recursos que lhes são fornecidos pelos técnicos publicitários e pelo marketing pessoal. Mas é uma apropriação seletiva, que pressupõe uma negociação tácita entre a mídia, que detém os instrumentos de produção da visibilidade social, e o político, que conhece ou intui os limites para além dos quais sua exposição pública se torna contraproducente. (MIGUEL, 2002, p. 17).

A partir desses conceitos, nesse texto são apresentados os resultados do grupo de pesquisa "Mídia, Política e Atores Sociais" da Universidade Estadual de Ponta Grossa, através de uma análise quantitativa com dados referentes à aparição das eleições municipais nas primeiras páginas durante os meses de agosto, setembro e outubro de 2008. A seguir são apresentadas a metodologia e os resultados do trabalho de campo, seguidas de uma conclusão a respeito da presença da campanha eleitoral de 2008 , em Ponta Grossa, nas primeiras páginas do Diário dos Campos e do Jornal da Manhã.

A pesquisa se restringe aos meses de agosto a outubro de 2008, pois é durante este período que acontece a campanha eleitoral oficial. Por se tratar de um período específico de campanha eleitoral, espera-se que os temas relacionados à política e políticas públicas tenham maior visibilidade. Para tanto, são analisados todos os textos publicados pelos jornais que citam pelo menos um dos candidatos oficiais à prefeitura do município em 2008. O paper está dividido em três partes sendo a primeira uma introdução teórica sobre o que é tratado pela pesquisa. A segunda parte do trabalho abrange a metodologia utilizada e os resultados dos dados coletados pela pesquisa empírica e na última parte faz-se uma breve consideração final acerca dos resultados e sua relação com as teorias utilizadas para embasar a pesquisa.

\section{Resultados}

Antes de discutir a cobertura dos jornais sobre a campanha política, é preciso localizar a conjuntura política para o período eleitoral em análise. Nas disputas municipais em 2008, em Ponta Grossa o candidato à reeleição, Pedro Wosgrau (PSDB) não teve maioria na preferência dos eleitores no primeiro turno, tendo ficado em vários momentos na segunda posição de preferências. Isso fez com que a disputa entre os dois mais votados, Wosgrau e Sandro Alex, fosse para o segundo turno, com pequena vantagem $(52,26 \%$ de votos válidos contra $47,74 \%)$ em favor de Pedro Wosgrau. Isso porque o candidato à reeleição, Pedro Wosgrau (PSDB), não tinha o governo bem avaliado pela população local. Tanto que no início da campanha de primeiro turno, a preferência eleitoral era majoritariamente favorável ao principal candidato de oposição, deputado estadual e ex-prefeito Jocelito Canto (PTB). Então, uma terceira força política, o radialista Sandro Alex (PPS), que disputava sua primeira eleição, apresentava constante crescimento nas intenções de voto. Durante a campanha, Canto manteve constantes quedas nas preferências eleitorais, enquanto Wosgrau conseguiu reagir na última fase do primeiro turno.

Com isso, o candidato à reeleição obteve $39,4 \%$ de votos válidos, garantindo sua continuidade na disputa. Em segundo lugar, com apenas $0,35 \%$ a mais de votos que o terceiro colocado, ficou Sandro Alex. Canto perdeu a chance de disputar o segundo turno, tendo sido derrotado pela segunda vez para a prefeitura de Ponta Grossa em disputa com Pedro Wosgrau, por menos de 600 votos em um universo de mais de mais de 180 mil votos válidos. Dos outros três concorrentes, o candidato do PT, Gerveson Silveira, ficou com quase $3 \%$ de votos válidos, enquanto 
A 'política' nos jornais durante período eleitoral: uma perspectiva da cobertura jornalística ...

outros dois concorrentes tiveram menos de $1 \%$ de votos no primeiro turno, juntos. A disputa no segundo turno continuou acirrada, com o candidato de oposição Sandro Alex iniciando a campanha à frente do candidato à reeleição. Apenas na última semana é que houve uma virada nas intenções de voto e Wosgrau foi eleito com $52,2 \%$ de votos válidos, contra $47,3 \%$ de Sandro Alex, ou seja, uma diferença de menos de cinco pontos percentuais. Essa disputa dinâmica ao longo da campanha, com alternância entre os melhores avaliados e pequenas diferenças nos resultados entre os principais candidatos indicam um acirrado debate na esfera pública. A questão é saber se essa dinâmica teve impactos no tipo de visibilidade que o tema recebeu pelos jornais locais. Para discutir esse ponto, a partir de agora se analisa o espaço de maior visibilidade dos jornais diários, que é a primeira página dos periódicos.

Em Londrina, a disputa eleitoral de 2008 foi ainda mais movimentada que a de Ponta Grossa. No primeiro turno o ex-prefeito e deputado estadual Antonio Belinati (PP) terminou em primeiro lugar, com $36,3 \%$ dos votos válidos. Em seguida veio Luis Carlos Hauly (PSDB), com 23,6\%. Na terceira colocação, com $22,9 \%$ de votos válidos, esteve Barbosa Neto (PDT), o que representa uma diferença de menos de 900 votos para Hauly em um universo de mais de 270 mil votos válidos. Assim como em Ponta Grossa, em Londrina a maior disputa do primeiro turno foi para definir o segundo colocado. No segundo turno Belinati venceu Hauly com $51,7 \%$ dos votos válidos. A questão é que após o segundo turno a justiça eleitoral cancelou o registro da candidatura de Belinatti após receber denúncia da promotoria eleitoral.

Acusado de improbidade administrativa em gestão anterior, Belinatti não pode assumir o novo mandato. Após a anulação dos votos destinados ao ex-prefeito, como não houve nenhum candidato com maioria de votos, foi marcada uma nova eleição entre o segundo e terceiro colocados em 2008. Na eleição suplementar entre Barbosa Neto e Luis Carlos Hauly, houve inversão dos resultados no primeiro turno. Beneficiado pela transferência de votos de Belinati, Barbosa Neto obteve $54,1 \%$ dos votos válidos na eleição suplementar, sendo considerado o prefeito eleito e assumindo o mandato no primeiro semestre de 2009. As análises da cobertura da Folha de Londrina realizada aqui se referem ao período compreendido entre o primeiro e segundo turnos em 2008, sem incluir a campanha suplementar.

Dos três municípios incluídos aqui, a eleição menos disputada foi a de Maringá. Nela, o então candidato à reeleição, Silvio Magalhães Barros II (PP) venceu no primeiro turno com 57\% de votos válidos, dispensando a continuidade da disputa em segundo turno. Atrás dele ficou o então deputado estadual Enio Verri (PT), com $21,9 \%$ dos votos válidos. Para permitir a relação com os demais jornais, o período analisado do Diário do Norte, principal veículo diário de Maringá, também inclui o mês de outubro.

A pesquisa buscou analisar os meses de agosto, setembro e outubro porque os mesmos englobam o período de campanha eleitoral, que no Brasil tem grande influência sobre os conteúdos transmitidos pelos meios de comunicação a respeito dos candidatos às prefeituras municipais. Além disso, os resultados aqui apresentados representam apenas uma parte da pesquisa maior que o grupo realiza comparando períodos eleitorais com não-eleitorais, que aqui não estão colocados. É importante estudar os períodos eleitorais, pois como Kinzo (2008) explica o período eleitoral, a democracia representativa e as políticas públicas são termos indissociáveis. Além disso, "a eleição é um método de escolha dos que devem governar e de legitimação de seu poder". (MANIN, 1995, p. 8). Logo, "para que os governados possam formar opinião sobre assuntos políticos é necessário que tenham acesso à informação política, o que supõe tornar públicas as decisões governamentais". (MANIN, 1995, p.11).

E para tornar públicas as ideias, propostas e decisões dos governantes, estes se utilizam dos meios de comunicação. Para Krieger (2008) em períodos eleitorais as dificuldades de cobertura aumentam, principalmente quando tem candidatos à reeleição. Pois, o jornalista deve tomar cuidado para não se tornar um instrumento de campanha do candidato e assim prejudicar o eleitor. Além disso, os meios de comunicação têm o papel de fornecer ao eleitor subsídios para que este possa optar entre uma ou outra proposta, tendo a informação mais completa e neutra possível. (CANELA, 2008).

Os jornalistas utilizam critérios de noticiabilidade para selecionarem aquilo que será 
notícia, dos acontecimentos que não serão. A noticiabilidade passa a ser entendida como o conceito que explica quais fatos sociais possuem características passíveis para se transformarem objeto de atenção dos jornalistas e integrarem o noticiário. É possível "definir o conceito de noticiabilidade como um conjunto de critérios e operações que fornecem a aptidão de merecer um tratamento jornalístico [...]". (TRAQUINA, 2005, p.63). Segundo Erbolato (1991) os critérios mais significativos são raridade, exclusividade, proximidade e interesse humano.

Para analisar a cobertura política jornalística levando em conta todos os pontos colocados até aqui, a pesquisa utilizou a metodologia de análise de conteúdo, conhecida também como Análise de Conteúdo (AC). Essa metodologia considera fatores quantitativos e qualitativos para que juntos deem um panorama maior sobre aquilo que se fala. Para a pesquisa em jornalismo, a análise de conteúdo é muito útil, pois é com auxílio desta que "ao analisarmos a frequência com que situações, pessoas e lugares aparecem na mídia podemos comparar o conteúdo publicado ou transmitido com os dados de referência", como "podemos estudar a imagem das mulheres, das crianças, dos idosos, e outros grupos". (HERSCOVITZ, 2007, p.124).

O trabalho analisa 1237 notícias publicadas por quatro jornais, durante os meses de agosto a outubro de 2008 a respeito da disputa eleitoral. O número de textos publicados varia entre os jornais. O Jornal da Manhã publicou 488 textos sobre a campanha eleitoral no período analisado, contra 445 do Diário dos Campos ambos de Ponta Grossa. Com menos da metade desses números individuais no mesmo período, o Diário do Norte publicou 160 matérias sobre a disputa para prefeito em Maringá, contra apenas 144 da Folha de Londrina (ver coluna Total na tabela 1).

Quanto aos formatos, os textos jornalísticos foram divididos em: chamada de primeira página, reportagem, charge/infográfico/ilustração, foto, coluna assinada, artigo assinado e editorial. Entraram na coleta de dados as informações que continham o nome de algum dos candidatos à prefeitos dos municípios de Londrina (Folha de Londrina), Maringá (Diário do Norte) e Ponta Grossa (Diário dos Campos e Jornal da Manhã), como por exemplo Antônio Belinati, Sílvio Barros e Pedro Wosgrau Filho. A distribuição por jornal consta na tabela 1 a seguir.

Tabela 1 - Formato das notícias sobre campanha eleitoral nos jornais

\begin{tabular}{c|c|c|c|c|c|c|c|c}
\hline Jornal & $\begin{array}{c}\text { Chamada } \\
1^{\text {a }} \text { página }\end{array}$ & $\begin{array}{c}\text { Repor } \\
\text { tagem }\end{array}$ & $\begin{array}{c}\text { Charge } \\
\text { info/ilust }\end{array}$ & Foto & $\begin{array}{c}\text { Coluna } \\
\text { assinada }\end{array}$ & $\begin{array}{c}\text { Artigo } \\
\text { assinado }\end{array}$ & $\begin{array}{c}\text { Edito } \\
\text { rial }\end{array}$ & Total \\
\hline $\begin{array}{c}\text { Diário do } \\
\text { Norte }\end{array}$ & $10(6,2)$ & $74(46,2)$ & $3(1,8)$ & $\begin{array}{c}10 \\
(6,2)\end{array}$ & $42(26,25)$ & $20(12,5)$ & $1(0,62)$ & $160(100)$ \\
\hline $\begin{array}{c}\text { Folha de } \\
\text { Londrina }\end{array}$ & $3(2,0)$ & $105(72,9)$ & 0 & $2(1,3)$ & $31(21,52)$ & 0 & $3(2,08)$ & $144(100)$ \\
\hline $\begin{array}{c}\text { Diário dos } \\
\text { Campos }\end{array}$ & $39(8,7)$ & $161(36,1)$ & $20(4,4)$ & $\begin{array}{c}30 \\
(6,7)\end{array}$ & $187(40,0)$ & 0 & $8(1,79)$ & $445(100)$ \\
\hline $\begin{array}{c}\text { Jornal da } \\
\text { Manhã }\end{array}$ & $32(6,5)$ & $208(42,6)$ & $75(15,3)$ & $\begin{array}{c}36 \\
(7,3)\end{array}$ & $104(21,3)$ & $9(1,84)$ & $24(4,91)$ & $488(100)$ \\
\hline
\end{tabular}

Fonte: Grupo de pesquisa em Mídia, Política e Atores Sociais (UEPG)

Como se percebe na tabela acima, o formato mais utilizado foi a reportagem. Isso porque este formato obteve 548 entradas se somados os quatro jornais ou $44,30 \%$ do total, com variação de $72,9 \%$ na Folha de Londrina até $36,1 \%$ no Diário dos Campos. A reportagem no meio jornalístico é um dos formatos mais importantes, pois é ela traz a junção de vários dados e informações, fazendo com que o leitor compreenda melhor aquilo que está se falando. É a notícia mais aprofundada e é onde a pesquisa faz-se necessária. A coluna assinada também teve grande presença na cobertura jornalística durante o período eleitoral, aparecendo em $29,42 \%$ dos jornais. Ela é o espaço destinado a algum especialista fixo, sobre algum tema específico como política e economia, por exemplo. $\mathrm{O}$ autor é mais importante que o assunto que 
está sendo tratado, e é quem assina o material e tem suas fontes de informação próprias. As maiores diferenças relativas estão no formato coluna assinada. No s dois jornais de Ponta Grossa, Diário dos Campos e Jornal da Manhã elas somam os maiores números absolutos, embora em termos percentuais apenas o Diário dos Campos destaque-se dos demais, com $40 \%$ do total da cobertura. Nota-se que em períodos eleitorais os textos mais elaborados, como as reportagens, são locais de grande visibilidade para os candidatos políticos. Isso porque eles apareceram na maior parte das vezes em reportagens e colunas assinadas. Excluindo o Diário dos Campos, nos outros três periódicos as reportagens foram responsáveis pela maior parte da cobertura eleitoral, com destaque para a Folha de Londrina, que apresentou $72,9 \%$ de sua cobertura nesse formato (tab. 1). Já em artigos assinados isso não aconteceu, pois em apenas $2,34 \%$ eles estavam presentes, em média, considerando que em dois periódicos (Diário dos Campos e Folha de Londrina) não houve nenhum artigo assinado que citasse o nome de pelo menos um candidato a prefeito.

Para saber quais são os temas nos quais os candidatos a prefeitos das cidades estavam presentes eles foram classificados entre campanha eleitoral, político institucional, economia, política social entre outros. Como nota-se, o principal candidato ao cargo, em Ponta Grossa, Pedro Wosgrau Filho (PSDB) esteve presente em 290 notícias somente no Diário dos Campos. Sendo que no Jornal da Manhã o mesmo apareceu 341 vezes. O que somados dá o equivalente a 631 vezes durante os três meses da campanha eleitoral. O que dá uma média de sete notícias por dia, somando os dois jornais. Isso demonstra que ambos jornais deram grande visibilidade ao candidato do PSDB durante a campanha, seja porque ele estava candidato enquanto ainda ocupava o cargo de prefeito, ou apenas por ser um dos principais concorrentes.

Tabela 2 - Tema Geral na cobertura política dos jornais de Ponta Grossa

\begin{tabular}{|c|c|c|c|}
\hline Jornal & Tema Geral & Wosgrau & Sandro Alex \\
\hline \multirow{10}{*}{$\begin{array}{l}\text { Diário dos } \\
\text { Campos }\end{array}$} & Campanha Eleitoral & $282(97,24)$ & $251(97,29)$ \\
\hline & Político institucional & $2(0,69)$ & $3(1,16)$ \\
\hline & Economia & $2(0,69)$ & $1(0,39)$ \\
\hline & Política Social & $1(0,34)$ & - \\
\hline & Infra-estrutura e meio ambiente & $1(0,34)$ & $1(0,39)$ \\
\hline & Política para Esporte & - & - \\
\hline & Cultura e variedades & $1(0,35)$ & - \\
\hline & Política Estadual, Nacional e ou Internacional & - & - \\
\hline & Outros & $1(0,34)$ & $2(0,77)$ \\
\hline & TOTAL & $290(100)$ & $258(100)$ \\
\hline \multirow{9}{*}{$\begin{array}{l}\text { Jornal da } \\
\text { Manhã }\end{array}$} & Campanha Eleitoral & $321(94,13)$ & $297(97,38)$ \\
\hline & Político institucional & $11(3,22)$ & $3(0,98)$ \\
\hline & Economia & - & - \\
\hline & Política Social & $3(0,88)$ & $1(0,33)$ \\
\hline & Infra-estrutura e meio ambiente & $3(0,88)$ & $1(0,33)$ \\
\hline & Ético-moral & $1(0,29)$ & $1(0,33)$ \\
\hline & Cultura e variedades & - & - \\
\hline & Outros & $2(0,58)$ & $2(0,65)$ \\
\hline & TOTAL & $341(100)$ & $305(100)$ \\
\hline
\end{tabular}

Fonte: Grupo de pesquisa em Mídia, Política e Atores Sociais (UEPG)

Já o adversário mais forte do candidato à reeleição, Sandro Alex (PPS) marcou presença em 258 matérias do jornal Diário dos Campos e em 305 do Jornal da Manhã, o que somados equivale a 563. Isso nos permite afirmar que o candidato do PPS também obteve muita visibilidade durante o período, pois a média de aparições nos jornais ficou em seis matérias diariamente. O que demonstra que houve diferença na quantidade de aparições dos candidatos, 
porém esta foi pequena. Também percebe-se que os dois principais candidatos de Ponta Grossa quando apareceram nos jornais locais estavam relacionados aos temas da campanha eleitoral. Pois, o índice de aparição neste tema chegou a quase 100 por cento das notícias e quase não teve diferença deste percentual nos dois jornais diferentes. A única diferença é que Sandro Alex esteve mais vezes nas notícias do Jornal da Manhã do que apareceu Pedro Wosgrau, mesmo assim a diferença percentual foi pequena.

Tabela 3 - Tema Geral na cobertura política dos jornais de Londrina e Maringá

\begin{tabular}{l|l|c|c}
\hline Jornal & Tema Geral & Belinati & Hauly \\
\hline \multirow{4}{*}{$\begin{array}{l}\text { Folha de } \\
\text { Londrina }\end{array}$} & Campanha Eleitoral & $90(90,9)$ & $78(90,7)$ \\
\cline { 2 - 4 } & Político institucional & $1(1)$ & $3(3,5)$ \\
\cline { 2 - 4 } & Ético-moral & $8(8,1)$ & $5(5,8)$ \\
\cline { 2 - 4 } & TOTAL & $99(100)$ & $86(100)$ \\
\hline \multirow{2}{*}{ Jornal } & Tema Geral & Sílvio Barros & Ênio Verri \\
\hline \multirow{4}{*}{$\begin{array}{l}\text { Diário do } \\
\text { Norte }\end{array}$} & Campanha Eleitoral & $85(85)$ & $64(83,1)$ \\
\cline { 2 - 4 } & Político institucional & $5(5)$ & $3(3,9)$ \\
\cline { 2 - 4 } & Política Social & $3(3)$ & $3(3,9)$ \\
\cline { 2 - 4 } & Infra-estrutura e meio ambiente & $6(6)$ & $6(7,8)$ \\
\cline { 2 - 4 } & Outros & $1(1)$ & $1(1,3)$ \\
\cline { 2 - 4 } & TOTAL & $100(100)$ & $77(100)$ \\
\hline
\end{tabular}

Fonte: Grupo de pesquisa em Mídia, Política e Atores Sociais (UEPG)

Observando a tabela 3 nota-se também que os jornais de Londrina e Maringá seguiram o mesmo padrão dos impressos de Ponta Grossa. Pois, a Folha de Londrina trouxe 90\% das matérias nas quais estava Antônio Belinati (PP) relacionada ao tema 'campanha eleitoral' e outras $8 \%$ relacionadas à ética e moral, pois o candidato naquele momento estava sendo investigado com suspeitas de desvio de dinheiro para caixa 2, durante sua campanha. Já seu maior concorrente Luiz Carlos Hauly (PSDB) esteve presente neste tema em cerca de $90 \%$ das notícias. O que é um número bastante significativo, como aconteceu com Belinati.

Já em Maringá, o Diário do Norte deu visibilidade a Sílvio Barros (PP) em $85 \%$ das matérias relacionadas também a campanha eleitoral. Já Ênio Verri (PT) apareceu em quase $85 \%$ das mesmas. Os dois candidatos do norte marcaram presença também em temas como a política institucional, políticas sociais, infra-estrutura urbana e meio ambiente. Isso demonstra como o tema campanha eleitoral tem grande relevância para os meios de comunicação e também para os candidatos, pois os jornais deram visibilidade aos candidatos principalmente relacionando-os a este tema e para os candidatos isso é importante porque ganhando visibilidades os mesmos ficam conhecidos pelos eleitores, o que pode ajudar (ou não) durante a busca por votos.

Além de verificar o tema geral também é necessário olhar para a forma de apuração que essas reportagens têm, pois entre apresentar o tema e interpretá-lo gerando maior debate e pesquisa sobre o mesmo há muita diferença. Por isso, foi analisado o enquadramento que as reportagens receberam, seguindo os estudos de Mauro Porto (2000). O autor separa quatro tipos de enquadramento que são: corrida de cavalos, personalista, temático e episódico. "O conceito de enquadramento tem sido utilizado para definir os 'princípios de seleção, ênfase e apresentação' usados por jornalistas para organizar a realidade e o noticiário", de acordo com Porto (2000, p. 12). 
A 'política' nos jornais durante período eleitoral: uma perspectiva da cobertura jornalística ...

Tabela 4 - Enquadramento das reportagens sobre campanha nos jornais

\begin{tabular}{c|c|c|c|c|c}
\hline Jornal & $\begin{array}{c}\text { Corrida de } \\
\text { Cavalos }\end{array}$ & Personalista & Temático & Episódico & Total \\
\hline Diário do Norte & $9(11,8)$ & $6(7,9)$ & $20(26,3)$ & $41(53,9)$ & $76(100)$ \\
\hline Folha de Londrina & $9(7,9)$ & $13(11,5)$ & $16(14,1)$ & $75(66,3)$ & $113(100)$ \\
\hline Diário dos Campos & $29(18)$ & $8(4,9)$ & $25(15,5)$ & $99(61,5)$ & $161(100)$ \\
\hline Jornal da Manhã & $32(15,3)$ & $7(3,3)$ & $30(14,4)$ & $139(66,8)$ & $208(100)$ \\
\hline
\end{tabular}

Fonte: Grupo de pesquisa em Mídia, Política e Atores Sociais (UEPG)

Como a tabela acima demonstra o enquadramento mais utilizado pelos jornalistas nas coberturas de reportagens durante o período eleitoral foi o episódico com 354 utilizações de um total de 558 reportagens coletadas, o que significa $63,44 \%$. As reportagens que assim foram classificadas se referem aquelas que não são interpretativas e estão centradas em descrever os fatos ou as declarações dos candidatos. A grande utilização desse tipo de reportagem pode ser explicada pelo fato de que os jornalistas geralmente têm muitas matérias para cobrir diariamente e falta de tempo para interpretar todas elas, o que faz com que a maioria seja mais descritiva. $O$ enquadramento temático foi o segundo mais utilizado e serve para cobrir as notícias em profundidade. Ele é o que mais interessa para a pesquisa, porque presta mais atenção aos padrões interpretativos que enfati- zam as posições e as propostas dos candidatos. "A ênfase das notícias que adotam este ponto de vista está nas plataformas e programas representados pelos diferentes candidatos". (PORTO, 2000 , p.13). Esse enquadramento representou $16 \%$ de toda a cobertura. A corrida de cavalos mostra como andam as pesquisas de opinião e sobre quem a população acha que vai ganhar as eleições. Representou $14,15 \%$ das reportagens, concentrando-se principalmente nos jornais de Ponta Grossa. O enquadramento personalista é aquele que enfoca o candidato, seus gostos, hobbies, família, e atitudes particulares e estava presente em mais de $6 \%$ das reportagens. Também se considera na análise as posições que os textos sobre a campanha ocuparam nas páginas dos jornais, por refletir o grau de importância que os editores dão para cada tema.

Tabela 5 - Posição das notícias sobre campanha eleitoral nas páginas dos jornais

\begin{tabular}{l|c|c|c|c}
\hline \multicolumn{1}{c|}{ Posição } & $\begin{array}{c}\text { Diário do } \\
\text { Norte }\end{array}$ & $\begin{array}{c}\text { Folha de } \\
\text { Londrina }\end{array}$ & $\begin{array}{c}\text { Diário dos } \\
\text { Campos }\end{array}$ & Jornal da Manhã \\
\hline Página Inteira & $4(2,5)$ & $9(6,5)$ & $3(0,68)$ & $7(1,53)$ \\
\hline Metade Superior & $20(12,3)$ & $8(5,8)$ & $34(7,7)$ & $36(7,87)$ \\
\hline Metade Inferior & $11(6,8)$ & $6(4,3)$ & $26(5,9)$ & $8(1,75)$ \\
\hline Quadrante Superior Direito & $42(25,9)$ & $13(9,4)$ & $175(39,8)$ & $154(33,69)$ \\
\hline Quadrante Superior Esquerdo & $37(22,8)$ & $52(37,6)$ & $74(16,8)$ & $98(21,44)$ \\
\hline Quadrante Inferior Direito & $19(11,7)$ & $24(17,4)$ & $91(20,7)$ & $93(20,35)$ \\
\hline Quadrante Inferior Esquerdo & $29(17,9)$ & $26(18,8)$ & $36(8,2)$ & $61(13,34)$ \\
\hline Total & $162(100)$ & $138(100)$ & $439(100)$ & $457(100)$ \\
\hline
\end{tabular}

Fonte: Grupo de pesquisa em Mídia, Política e Atores Sociais (UEPG) 
$\mathrm{Na}$ tabela 5 fica evidenciado que as notícias dos três meses de coleta se concentraram no quadrante superior direito e no quadrante superior esquerdo dos jornais. O que indica que as matérias obtiveram bastante relevância durante o período, pois estavam na primeira dobra do jornal, que é o local onde geralmente se tem menos matérias devido ao espaço ocupado pelas manchetes. Se reunirmos os dois indicadores (quadrante superior direito e o esquerdo) percebemos que eles ocuparam aproximadamente
$54 \%$ do espaço dos jornais, o que mais uma vez demonstra sua relevância. Também pesquisamos as fontes de informação consultadas pelos jornalistas para a produção das matérias e assim, percebe-se que a maioria das fontes utilizadas (mais de 70\% em todos os jornais) representa instituições públicas ou privadas, e não estavam falando apenas em seu próprio nome, mas sim institucionalmente, como, por exemplo, os candidatos a prefeito.

Tabela 6 - Origem das fontes além dos candidatos na cobertura eleitoral

\begin{tabular}{l|c|c|c|c|c}
\hline \multicolumn{1}{|c|}{ Origem da Fonte } & $\begin{array}{c}\text { Oficial } \\
\text { habitual }\end{array}$ & $\begin{array}{c}\text { Disruptiva } \\
\text { Social }\end{array}$ & $\begin{array}{c}\text { Cidadão } \\
\text { individualizado }\end{array}$ & $\begin{array}{c}\text { Próprio } \\
\text { jornalista }\end{array}$ & Total \\
\hline Diário do Norte & $52(73,2)$ & $1(1,4)$ & $2(2,8)$ & $16(22,5)$ & $71(100)$ \\
\hline Folha de Londrina & $77(83,7)$ & $1(1,0)$ & $14(15,2)$ & - & $92(100)$ \\
\hline Diário dos Campos & $172(70,2)$ & $4(1,6)$ & $6(2,4)$ & $63(25,7)$ & $245(100)$ \\
\hline Jornal da Manhã & $133(80,1)$ & $1(0,6)$ & $6(3,6)$ & $26(15,6)$ & $166(100)$ \\
\hline
\end{tabular}

Fonte: Grupo de pesquisa em Mídia, Política e Atores Sociais (UEPG)

Além da tabela 6 , a pesquisa também verificou a segunda fonte mais citada. Em todos os jornais é o próprio jornalista, estando presente em $18 \%$ das matérias, em média. Ele estava em momentos em que o repórter, sem nenhuma outra citação de fonte, apresentava ou descrevia a situação a partir de observação direta ou memória histórica, como por exemplo, quando o repórter acompanhou a reunião do partido, não citou outras fontes e expôs sua opinião. As fontes disruptivas são aquelas que dão opiniões a partir de eventos ou crises sociais que geraram algum tipo de confronto ou instabilidade social. O fato social era maior do que a fonte que o expressava. Esse tipo de fonte apareceu em pouco mais de $1 \%$. Já o cidadão individualizado estava presente em $4,88 \%$ das matérias, quando foi utilizada a fala de entrevistados. Aqui, o destaque é a Folha de Londrina, que apresenta $15,2 \%$ das fontes citadas como sendo "cidadão individualizado".

Nota-se que os entrevistados mais recorrentes para os jornalistas continuam sendo aqueles que ocupam cargos oficiais e que falam em nome do governo ou de instituições nas quais são os representantes. Ao apresentar mais fontes oficiais do que disruptivas ou o próprio cida- dão comum, o jornalista tende a transmitir a visão oficial do governo e não equilibrá-la com outras. O que é uma perda de pluralidade de pontos de vistas sobre o mesmo acontecimento. Mas, como o tema campanha eleitoral foi o que mais esteve presente nos quatro jornais (quando algum candidato apareceu) entende-se também que eles foram algumas das fontes de informação, sendo assim é natural que haja maior número de fontes oficiais quando o tema tratado fala sobre política e cargos do governo.

\section{Considerações finais}

Percebe-se com esta pesquisa que em períodos de campanha eleitoral temas referentes à disputa eleitoral são recorrentes nos jornais impressos. Isso porque os quatro jornais observados trouxeram o tema 'campanha para prefeito' com maior destaque. Pode-se alegar isto a partir da junção de dados que demonstram a relevância das notícias de política durante os meses de agosto, setembro e outubro de 2008. Pois, mais de $50 \%$ das matérias que falavam 
sobre a política e sobre os candidatos estavam localizadas na primeira dobra dos jornais. Local este que atrai grande parte da atenção do leitor e onde se localizam as manchetes e temas mais relevantes do dia.

Além disso, esses assuntos receberam tratamento especial por parte dos jornalistas e editores dos jornais, visto que apareceram em formatos como a reportagem em $45 \%$ das matérias. Outro aspecto que comprova que a campanha eleitoral e os principais candidatos a prefeitos das cidades de Ponta Grossa, Londrina e Maringá tiveram grande visibilidade é o fato de aproximadamente $65 \%$ das notícias trataram o tema com profundidade. Mesmo quando não interpretavam os dados e aspectos, elas traziam as notícias em forma de reportagem e em locais privilegiados da página dos impressos. Quanto aos entrevistados pelos repórteres, fica claro que os oficiais têm destaque. Uma explicação plausível para isso é porque os temas mais recorrentes foram 'campanha para prefeito' e a 'corrida eleitoral' que estão diretamente interligados com as fontes de informação. Os temas tratam diretamente de cargos políticos e das dificuldades que os futuros prefeitos teriam que solucionar, por isso entende-se que o número de entrevistados pertencentes ao governo ou que ocupam cargo oficial tende a ser maior, porém ao consultar apenas as fontes oficiais o jornal não dá abertura suficiente para o cidadão comum e com isso há pouca pluralidade de vozes.

Percebe-se também que os jornais podem ter ajudado os eleitores a reconhecer os principais candidatos aos cargos de prefeito de suas cidades, pois nos quatro veículos estudados os dois principais concorrentes a prefeito aparecem em mais de $80 \%$ das matérias, sendo que os impressos de Ponta Grossa foram aqueles que mais se destacaram quanto isso, pois Pedro Wosgrau e Sandro Alex tiveram grande visibilidade (ou seja, apareceram em mais quase todas as notícias e reportagens veiculadas sobre a campanha eleitoral). Assim, pode-se dizer que a política e campanha eleitoral têm visibilidade significativa nos jornais paranaenses analisados para o período eleitoral de 2008 - com diferenças entre os locais do município de Ponta Grossa (Jornal da Manhã e Diário dos Campos) que apresentaram um número significativamente maior de textos sobre a disputa para a prefeitura local. De qualquer maneira, os resultados permitem afirmar que a análise quantitativa da cobertura eleitoral é um campo ainda pouco explorado nas pesquisas em jornalismo, embora apresente grande potencial explicativo sobre o comportamento dos periódicos em coberturas especiais, que é o caso de uma campanha política. Futuras pesquisas aplicadas podem ajudar a compreender melhor a presença do tema "política" nas páginas dos jornais.

\section{Referências}

CANELA, Guilherme. A cobertura jornalística das políticas públicas sociais: elementos para debate. In:__. (Org.). Políticas públicas sociais e os desafios para o jornalismo. São Paulo: ANDI; Cortez Editora, 2008.

ERBOLATO, Mário. Técnicas de codificação em jornalismo: redação, captação e edição no Jornal Diário. São Paulo: Ática, 1991.

HABERMAS, Jürgen. Mudança estrutural da esfera pública: investigações quanto a uma categoria da sociedade burguesa. Tradução de Flávio R. Kothe. Rio de Janeiro: Tempo Brasileiro, 2003.

HERSCOVITZ, Heloiza Golbspan. Análise de conteúdo em jornalismo. In: LAGO, Cláudia; BENETTI, Márcia (Orgs.). Metodologia de pesquisa em jornalismo. Rio de Janeiro: Vozes, 2007.

KINZO, Maria D'Alva Gil. O processo eleitoral e as políticas públicas sociais. In: CANELA, Guilherme (Org.). Políticas públicas sociais e os desafios para o jornalismo. São Paulo: Cortez Editora, 2008.

KUNCZIK, Michael. Conceitos de jornalismo: norte e sul: manual de Comunicação. Tradução de Rafael Varela Júnior, 2. ed. São Paulo: Editora da Universidade de São Paulo, 2002.

MANIN, Bernard. As metamorfoses do governo representativo. Revista Brasileira de Ciências Sociais. Associação Nacional de Pós-Graduação e Pesquisa em Ciências Sociais, n.29, ano 10, outubro de 1995.

McCOMBS, Maxwell. Building consensus: the news media's agenda-setting roles. University of Texas at Austin. Political Communication, v.1; n.4; p.433443, 1997. 
MIGUEL, Luis Felipe. Os meios de comunicação e a prática política. Lua Nova: Revista de Cultura e Política, n. 55-56. São Paulo, 2002.

WOLF, Mauro. Teorias da comunicação. Tradução de Maria Jorge Vilar de Figueiredo. 9. ed. Portugal:

Presença, 2006. 